\title{
VEGF: Potential therapy for renal regeneration
}

\author{
Alejandro R. Chade, $\mathrm{MD}^{1,2}$
}

Address: The Department of Physiology and Biophysics ${ }^{1}$, Center for Excellence in Cardiovascular-Renal Research, and the Department of Medicine $^{2}$, University of Mississippi Medical Center, 2500 North State Street, Jackson, MS, 39216-4505

Email: achade@umc.edu

FI000 Medicine Reports 2012, 4:I (doi:10.34I0/M4-I)

This is an open-access article distributed under the terms of the Creative Commons Attribution-Non Commercial License (http://creativecommons.org/licenses/by-nc/3.0/legalcode), which permits unrestricted use, distribution, and reproduction in any medium, provided the original work is properly cited. You may not use this work for commercial purposes.

The electronic version of this article is the complete one and can be found at: http://fl $000 . c o m / r e p o r t s / m / 4 / I$

\begin{abstract}
Vascular endothelial growth factor (VEGF) plays a central role in angiogenesis. A number of studies have focused on its role in health and disease and discussed the possibility of VEGF as both a therapeutic tool and target based on its specific actions on vascular proliferation and cell survival. On one side, anti-VEGF therapies are at the fore-front of treatment of many solid tumors, but blockade of VEGF carries collateral effects such as hypertension and renal damage largely due to abnormalities in the microvasculature. On the other hand, recent clinical and experimental evidence has shown the feasibility of using VEGF administration to protect ischemic tissues such as the myocardium or the kidney via stimulation of microvascular proliferation and repair. In this commentary, we discuss the possibility and potential mechanisms of using intra-renal administration of VEGF to preserve the renal microcirculation and, consequently, decrease progressive renal injury in chronic renovascular disease. Targeted administration of VEGF may constitute a novel stand-alone or co-adjuvant intervention with the potential to become a part of a comprehensive plan to protect renal function.
\end{abstract}

\section{Introduction}

Chronic kidney disease affects over $15 \%$ of the US adult population [1]. Chronic kidney disease patients have a five fold increase in co-morbid conditions and 50\% higher rate of hospitalization compared to the general population [1]. Chronic renovascular disease is a progressive disease that currently accounts for up to $16 \%$ of all cases of chronic kidney disease and end-stage renal disease $[2,3]$, with an incidence which increases with age and makes it a major health problem and economic burden worldwide. The main etiology of chronic renovascular disease is renal artery narrowing/stenosis (usually due to atherosclerosis), which currently affects $18-40 \%$ of patients older than 65 [2]. The most frequent therapeutic approach to treat renal artery stenosis is by catheterbased interventions via renal angioplasty. However, despite its increasing use and technical success in resolving a renal vascular obstruction, recovery of renal function and/or the resolution of hypertension are still observed in about one third of the patients.
Despite major advances in imaging and interventional techniques, little progress has been made in improving the relatively poor outcomes of catheter-based interventions in patients with chronic renovascular disease. Thus, identification of potential therapies targets to slow, stop or even reverse the progressive renal injury seen in chronic renovascular disease would provide a huge benefit. New experimental models are giving us hope that we may find new approaches to stop the continuous increase in end stage renal disease observed for the past 2 decades [4]. Some of these approaches are targeted therapeutic interventions. For example, cell-based therapy for the kidney has gained momentum in the past 5 years. The use of pluripotent progenitor cells looks like a promising and relatively safe renoprotective therapy [5-7], although the mechanism of action is still under debate. By incorporation into the tissue and inducing powerful autocrine and paracrine stimulation of surrounding cells around the damaged renal tissue [8], progenitor cells trigger a prolonged cascade of events 
leading to increased neovascularization and decreased inflammation and fibrosis.

One prominent cytokine stimulated in the kidney by these cell-based interventions is vascular endothelial growth factor (VEGF) [7]. VEGF is a pivotal angiogenic and pro-survival factor, which operates in concert with other factors to promote cell division, migration, endothelial cell survival, and vascular sprouting. The net effect is to dynamically generate, repair, and maintain microvascular networks, which extend from major vessels to play crucial roles in diffusion exchange of nutrients and metabolites in virtually all tissues in the body. VEGF also promotes migration of endothelial cell progenitors $[9,10]$, and these include vascular proliferation not only during developmental phases but also in tissues subjected to an ischemic insult. The angiogenic effects of VEGF and its potential application as a renal therapeutic tool are the main focus of this commentary. For a comprehensive review of the biology of VEGF, which is beyond the scope of this commentary, please refer to $[11,12]$.

\section{Anti-VEGF therapies underline its importance}

The clear-cut actions of VEGF in angiogenesis have been the engine for copious research on targeting VEGF in cancer, where it plays a central role in generating blood vessels that promote the growth of the tumor. AntiVEGF therapies are already part of the first line of treatment in colon cancer [13] and their use in other types of solid tumors is under extensive investigation $[14,15]$. However, this intervention is not free of collateral damage: adverse effects include hypertension and renal damage, which are possibly due, in part, to significant microvascular damage in the renal parenchyma [16]. Furthermore, it has been reported that downregulation of the VEGF pathway in normal organs can lead to microvascular disturbances and even regression of blood vessels, which could be compounded by concurrent pathological conditions [17]. Beyond raising the need for caution in the use of these agents, these findings emphasize the importance of this key angiogenic cytokine in health and disease.

\section{How can VEGF induce renoprotection?}

Structural damage, dysfunction, and/or loss of the microvessels, known as microvascular disease, is a key contributor to the progression of organ damage [18-22]. Extending from major vessels to ensure diffusion exchange of nutrients and metabolites in the tissues, microvessels are vital for the normal function of any organ. Previous experimental and clinical evidence has shown that VEGF administration protects the microcirculation in different pathological milieus, such as in the ischemic myocardium $[23,24]$ and hind-limb ischemia [25]. Furthermore, seminal work by Kang et al. [26] and David Basile's group $[27,28]$ in rodents has shown the importance of renal VEGF for slowing the progression of renal injury as well as the feasibility of using VEGF therapy as a renoprotective tool.

These findings suggest that VEGF has a central role in the kidney and give us the rationale to use an intra-renal administration of exogenous VEGF as a potential therapy to protect the kidney. Using a model of chronic renal artery stenosis as a surrogate of chronic renovascular disease, our studies have demonstrated that a progressive microvascular loss in the stenotic kidney correlates with progressive renal damage, that renal VEGF progressively decreases in the kidney, and that the decrease in VEGF in turn correlates with the progressive deterioration of renal function and microvascular rarefaction in the stenotic kidney [29-32]. Administration of VEGF was shown to be beneficial. Intra-renal VEGF improved renal function and restored microvascular density by stimulating microvascular proliferation in the stenotic kidney, underscoring the importance of renal microvascular integrity for renal function. A single intra-renal administration of VEGF in the stenotic kidney augmented the glomerular and tubular expression of this cytokine, and also increased the expression of its key mediators. For example, intrarenal administration of VEGF may promote an increase in Akt, a key pro-survival factor, and Ang-1/Tie-2 [30], which together with VEGF [33] play important roles in promoting vascular proliferation and accelerating the maturation of the newly generated vessels [34,35] as well as in the mobilization and homing of cell progenitors into ischemic tissues to promote neovascularization [36]. Another pivotal mediator of VEGF that we observed to be increased by this intervention is endothelial nitric oxide synthase, which may augment nitric oxide bio-availability [30]. Endothelial nitric oxide synthase-derived nitric oxide plays an important role in the initial microvascular sprouting induced by VEGF [37] and the nitric oxide-VEGF axis protects tubular and glomerular cells from injury [38]. Overall, our work indicates that intra-renal administration of VEGF is a feasible therapeutic approach for the ischemic kidney. It largely restored the VEGF-angiogenic cascade, stimulating microvascular proliferation and probably the repair that preserved the renal microcirculation [30]. Functionally, this resulted in preservation of the microcirculation and renal function, decreased renal fibrosis, and improved responses to renal angioplasty $[29,30]$.

\section{The road ahead}

Although others $[26,28]$ and we $[29,30]$ have shown that intra-renal administration of VEGF improved the 
function of the stenotic kidney, caution should be exercised in translating this into clinical practice $[29,30]$. First, VEGF is also a potent vasodilator that may decrease blood pressure and this could reduce its tolerance should it be used in clinical practice. However, we used the maximally tolerated dose in our studies that was shown to be effective in inducing vascular proliferation and increasing perfusion of the ischemic myocardium in humans without causing adverse collateral effects [24]. Other than a minimal and transient decrease in blood pressure in the animals, the intra-renal administration of VEGF was free of adverse effects in our studies, offering the possibility of increasing the frequency of administration if needed. Second, VEGF may increase the permeability of newly generated vessels. High permeability may decrease the functionality of these neovessels and may in turn facilitate renal injury in chronic renovascular disease by allowing the leakage of injurious cytokines to the extra-vascular space. Finally, since VEGF has been shown to promote tumor growth and it has been suggested to play a role in promoting atherosclerosis, refinement of the technical side of its administration (dose, route, frequency) and careful selection and follow-up of the patients is crucial to avoid undesired effects of this intervention should it progress into clinical trials. Although I am aware that the swine model used in our studies may represent the very early stage of chronic renovascular disease, it did show that VEGF administration reduced renal damage in the stenotic kidney. This intervention promoted microvascular proliferation, maturation, and cell survival. Likely, not only by improving its renal bioavailability but also by stimulating key players in the VEGF-induced angiogenic cascade (e.g. endothelial nitric oxide synthase, Akt, angiopoietins). These results suggest that the multi-step process of angiogenesis was stimulated in the kidney (Figure 1), and they also indicate that preserving the renal microvascular architecture was renoprotective [29,30].

\section{Conclusion}

It is possible that severity of renal microvascular disease is underestimated at the moment in treatment of chronic renovascular disease. The process of microvascular damage may define the "window of opportunity" to successfully intervene in patients with chronic renovascular disease and could be a major player behind the relatively poor outcomes of renal angioplasty and the progressive nature of chronic renovascular disease. Accurate assessment of the renal microvascular density and function in humans is indeed challenging. However, clinically available high-resolution imaging techniques to quantify microvascular distribution and evaluation of microvascular function (e.g. ultrasound, CT imaging) could serve as tools to better determine the severity of
Figure I: Schematic illustration summarizing the effects of an intra-renal administration of VEGF in the stenotic kidney, in a model of chronic RVD

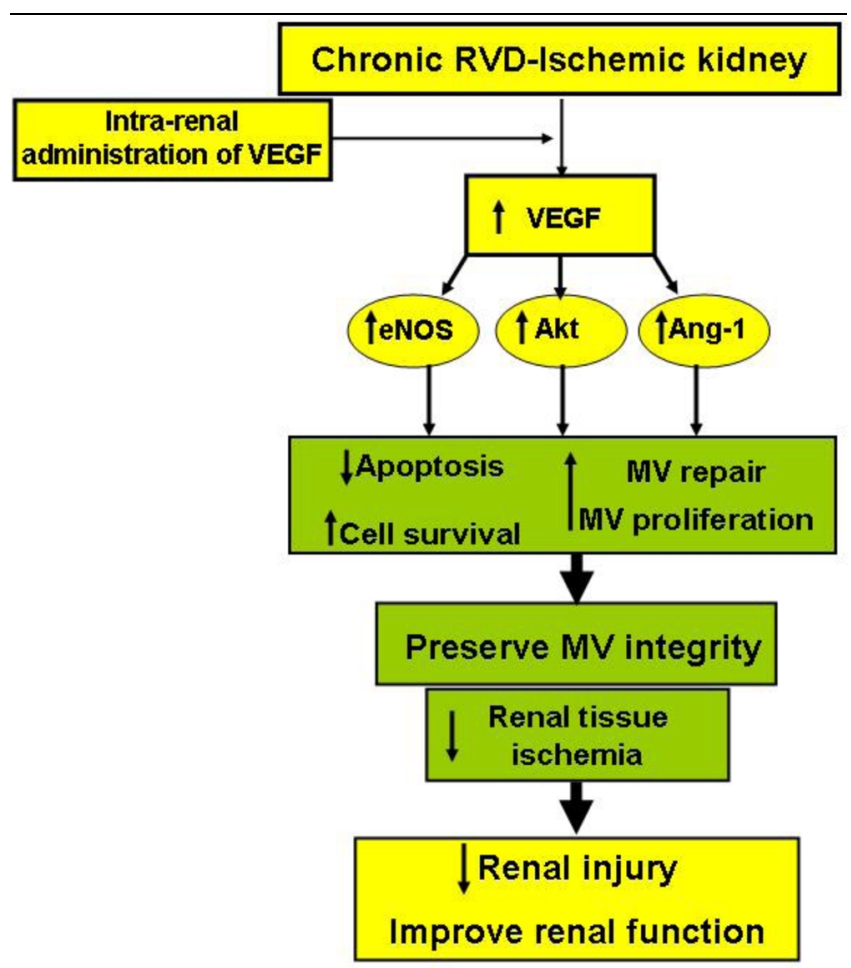

Exogenous VEGF stimulated angiogenic and pro-survival mediators that promote cell survival and MV proliferation and repair, consequently decreasing renal injury and improving renal function. Abbreviations: RVD: renovascular disease; MV: microvascular; eNOS: endothelial nitric oxide synthase; Ang-I: angiopoietin-I.

microvascular and renal damage and thereby help to predict the outcomes of renal angioplasty. Targeted use of VEGF has shown promising renoprotective effects in clinically relevant experimental settings $[26,29,30]$. Those results may inform the carefully designed prospective experimental and clinical studies that are needed to determine the feasibility and optimal therapeutic use of VEGF, both as a stand-alone treatment or, possibly, as a coadjuvant intervention for the treatment of patients with chronic renovascular disease.

\section{Abbreviation \\ VEGF, Vascular endothelial growth factor.}

\section{Competing interests}

The author declares that he has no competing interests.

\section{Acknowledgements}

This work was supported by grant HL095638 from the National Institutes of Health. 


\section{References}

I. US Renal Data System: USRDS 2010 Annual Data Report; Atlas of End-Stage Renal Disease in the United States. Bethesda, MD, National Institutes of Health, National Institute of Diabetes, and Digestive and Kidney Diseases; 20II. [http://www.usrds.org/atlas I0.aspx]

2. Dworkin LD, Murphy $\mathrm{T}$ : Is there any reason to stent atherosclerotic renal artery stenosis? Am J Kidney Dis 2010, 56:259-63.

FI000 Factor 6

Evaluated by Alejandro Chade $15 \mathrm{Dec} 20 \mathrm{II}$

3. Hansen KJ, Edwards MS, Craven TE, Cherr GS, Jackson SA, Appel RG, Burke GL, Dean RH: Prevalence of renovascular disease in the elderly: a population-based study. J Vasc Surg 2002, 36:443-5I.

4. US Renal Data System: USRDS 2005 Annual Data Report; Atlas of End-Stage Renal Disease in the United States. Bethesda, MD, National Institutes of Health, National Institute of Diabetes, and Digestive and Kidney Diseases; 2005. [http://www. usrds.org/atlas05.aspx]

5. Uchimura H, Marumo T, Takase O, Kawachi H, Shimizu F, Hayashi M, Saruta T, Hishikawa K, Fujita T: Intrarenal injection of bone marrow-derived angiogenic cells reduces endothelial injury and mesangial cell activation in experimental glomerulonephritis. J Am Soc Nephrol 2005, 16:997-1004.

FI000 Factor 6

Evaluated by Alejandro Chade $15 \mathrm{Dec} 2011$

6. Chade AR, Zhu X, Lavi R, Krier JD, Pislaru S, Simari RD, Napoli C, Lerman A, Lerman LO: Endothelial progenitor cells restore renal function in chronic experimental renovascular disease. Circulation 2009, I 19:547-57.

7. Ma YY, Sun D, Li J, Yin ZC: Transplantation of endothelial progenitor cells alleviates renal interstitial fibrosis in a mouse model of unilateral ureteral obstruction. Life Sci 20II, 86:798-807.

FI000 Factor 6

Evaluated by Alejandro Chade 15 Dec 2011

8. Goligorsky MS, Kuo MC, Patschan D, Verhaar MC: Review article: endothelial progenitor cells in renal disease. Nephrology (Carlton) 2009, I 4:291-7.

9. Moore MA, Hattori K, Heissig B, Shieh JH, Dias S, Crystal RG, Rafii S: Mobilization of endothelial and hematopoietic stem and progenitor cells by adenovector-mediated elevation of serum levels of SDF-I, VEGF, and angiopoietin-I. Ann N Y Acad Sci 200I, 938:36-45.

FI000 Factor 6

Evaluated by Alejandro Chade $15 \mathrm{Dec} 201 \mathrm{I}$

10. Zisa D, Shabbir A, Mastri M, Suzuki G, Lee T: Intramuscular VEGF repairs the failing heart: role of host-derived growth factors and mobilization of progenitor cells. Am J Physiol Regul Integr Comp Physiol 2009, 297:R I503-I5.

FI000 Factor 6

Evaluated by Alejandro Chade $15 \mathrm{Dec} 201 \mathrm{I}$

II. Ferrara N, Gerber HP, LeCouter J: The biology of VEGF and its receptors. Nat Med 2003, 9:669-76.

12. Eremina V, Quaggin SE: The role of VEGF-A in glomerular development and function. Curr Opin Nephrol Hypertens 2004, 13:9-15.

13. Ferrara N, Hillan KJ, Gerber HP, Novotny W: Discovery and development of bevacizumab, an anti-VEGF antibody for treating cancer. Nat Rev Drug Discov 2004, 3:391-400.

14. Jain RK, Duda DG, Clark JW, Loeffler JS: Lessons from phase III clinical trials on anti-VEGF therapy for cancer. Nat Clin Pract Oncol 2006, 3:24-40.
15. Osada T, Chong G, Tansik R, Hong T, Spector N, Kumar R, Hurwitz HI, Dev I, Nixon AB, Lyerly HK, Clay T, Morse MA: The effect of anti-VEGF therapy on immature myeloid cell and dendritic cells in cancer patients. Cancer Immunol Immunother 2008, 57: III5-24.

16. Eremina V, Jefferson JA, Kowalewska J, Hochster $H$, Haas $M$, Weisstuch J, Richardson C, Kopp JB, Kabir MG, Backx PH, Gerber HP, Ferrara N, Barisoni L, Alpers CE, Quaggin SE: VEGF inhibition and renal thrombotic microangiopathy. $N$ Engl J Med 2008, 358: | | 29-36.

\section{Changes Clinical Practice}

FI000 Factor II

Evaluated by Alejandro Chade 10 Oct 2008, Ramon Bonegio and David Salant 27 May 2008, Terence H Cook 08 Apr 2008, Andrew Davenport 17 Mar 2008

17. Kamba T, McDonald DM: Mechanisms of adverse effects of antiVEGF therapy for cancer. Br J Cancer 2007, 96:1788-95.

FI000 Factor 6

Evaluated by Alejandro Chade $15 \mathrm{Dec} 201 \mathrm{I}$

18. Krentz AJ, Clough G, Byrne CD: Interactions between microvascular and macrovascular disease in diabetes: pathophysiology and therapeutic implications. Diabetes Obes Metab 2007, 9:78|-91.

FI000 Factor 6

Evaluated by Alejandro Chade 15 Dec 2011

19. Uzu T, Kida Y, Shirahashi N, Harada T, Yamauchi A, Nomura M, Isshiki K, Araki S, Sugimoto T, Koya D, Haneda M, Kashiwagi A, Kikkawa R: Cerebral microvascular disease predicts renal failure in type 2 diabetes. J Am Soc Nephrol 2010, 21:520-6.

FI000 Factor 8

Evaluated by Takahiko Nakagawa I 2 Jan 201 I, Alejandro Chade 10 Feb 2010

20. Kuo L, Davis MJ, Cannon MS, Chilian WM: Pathophysiological consequences of atherosclerosis extend into the coronary microcirculation. Restoration of endothelium-dependent responses by L-arginine. Circ Res 1992, 70:465-76.

FI000 Factor 6

Evaluated by Alejandro Chadel5 Dec 2011

2I. Johnson RJ, Rodriguez-Iturbe B, Schreiner GF, Herrera-Acosta J: Hypertension: a microvascular and tubulointerstitial disease. J Hypertens Suppl 2002, 20:SI-7.

FI000 Factor 6

Evaluated by Alejandro Chade I5 Dec 20II

22. Zhu XY, Daghini E, Chade AR, Versari D, Krier JD, Textor KB, Lerman A, Lerman LO: Myocardial microvascular function during acute coronary artery stenosis: effect of hypertension and hypercholesterolaemia. Cardiovasc Res 2009, 83:37II-80.

23. Hendel RC, Henry TD, Rocha-Singh K, Isner JM, Kereiakes DJ, Giordano FJ, Simons M, Bonow RO: Effect of intracoronary recombinant human vascular endothelial growth factor on myocardial perfusion: evidence for a dose-dependent effect. Circulation 2000, 101:118-21.

FI000 Factor 6

Evaluated by Alejandro Chade $15 \mathrm{Dec} 201 \mathrm{I}$

24. Henry TD, Rocha-Singh K, Isner JM, Kereiakes DJ, Giordano FJ, Simons M, Losordo DW, Hendel RC, Bonow RO, Eppler SM, Zioncheck TF, Holmgren EB, McCluskey ER: Intracoronary administration of recombinant human vascular endothelial 
growth factor to patients with coronary artery disease. Am Heart J 200I, I42:872-80.

FI000 Factor 6

Evaluated by Alejandro Chade 15 Dec 2011

25. Wafai R, Tudor EM, Angus JA, Wright CE: Vascular effects of FGF-2 and VEGF-B in rabbits with bilateral hind limb ischemia. J Vasc Res 2009, 46:45-54.

FI000 Factor 6

Evaluated by Alejandro Chade 15 Dec 2011

26. Kang DH, Hughes J, Mazzali M, Schreiner GF, Johnson RJ: Impaired angiogenesis in the remnant kidney model: II. Vascular endothelial growth factor administration reduces renal fibrosis and stabilizes renal function. J Am Soc Nephrol 200I, I2: 1448-57.

FI000 Factor 8

Evaluated by Alejandro Chade $15 \mathrm{Dec} 201 \mathrm{I}$

27. Basile DP, Fredrich K, Chelladurai B, Leonard EC, Parrish AR: Renal ischemia reperfusion inhibits VEGF expression and induces ADAMTS-I, a novel VEGF inhibitor. Am J Physiol Renal Physiol 2008, 294:F928-36.

FI000 Factor 8

Evaluated by Alejandro Chade $15 \mathrm{Dec} 201 \mathrm{I}$

28. Leonard EC, Friedrich JL, Basile DP: VEGF-I2I preserves renal microvessel structure and ameliorates secondary renal disease following acute kidney injury. Am J Physiol Renal Physiol 2008, 295:FI648-57.

FI000 Factor 8

Evaluated by Alejandro Chade 15 Dec 2011

29. Chade AR, Kelsen S: Renal microvascular disease determines the responses to revascularization in experimental renovascular disease. Circ Cardiovasc Interv 2010, 3:376-83.

30. Iliescu R, Fernandez SR, Kelsen S, Maric C, Chade AR: Role of renal microcirculation in experimental renovascular disease. Nephrol Dial Transplant 2010, 25:1079-87.

31. Chade AR, Zhu X, Mushin OP, Napoli C, Lerman A, Lerman LO: Simvastatin promotes angiogenesis and prevents microvascular remodeling in chronic renal ischemia. Faseb J 2006, 20: I 706-8.

32. Zhu XY, Chade AR, Rodriguez-Porcel M, Bentley MD, Ritman EL, Lerman A, Lerman LO: Cortical microvascular remodeling in the stenotic kidney: role of increased oxidative stress. Arterioscler Thromb Vasc Biol 2004, 24:1854-9.
33. Findley CM, Cudmore MJ, Ahmed A, Kontos CD: VEGF induces Tie2 shedding via a phosphoinositide 3-kinase/Akt dependent pathway to modulate Tie2 signaling. Arterioscler Thromb Vasc Biol 2007, 27:2619-26.

FI000 Factor 6

Evaluated by Alejandro Chade 15 Dec 2011

34. Chen JX, Stinnett A: Disruption of Ang-I/Tie-2 signaling contributes to the impaired myocardial vascular maturation and angiogenesis in type II diabetic mice. Arterioscler Thromb Vasc Biol 2008, 28:1606-13.

FI000 Factor 6

Evaluated by Alejandro Chade 15 Dec 2011

35. Somanath PR, Chen J, Byzova TV: Aktl is necessary for the vascular maturation and angiogenesis during cutaneous wound healing. Angiogenesis 2008, I I:277-88.

FI000 Factor 6

Evaluated by Alejandro Chade 15 Dec 2011

36. Saif J, Schwarz TM, Chau DY, Henstock J, Sami P, Leicht SF, Hermann PC, Alcala S, Mulero F, Shakesheff KM, Heeschen C, Aicher A: Combination of injectable multiple growth factorreleasing scaffolds and cell therapy as an advanced modality to enhance tissue neovascularization. Arterioscler Thromb Vasc Biol 2010, 30:1897-1904.

FI000 Factor 6

Evaluated by Alejandro Chade 15 Dec 2011

37. Lu Y, Xiong $Y$, Huo $Y$, Han J, Yang $X$, Zhang $R$, Zhu DS, KleinHessling S, Li J, Zhang $X$, Han X, Li Y, Shen B, He Y, Shibuya M, Feng GS, Luo J: Grb-2-associated binder I (Gabl) regulates postnatal ischemic and VEGF-induced angiogenesis through the protein kinase A-endothelial NOS pathway. Proc Natl Acad Sci U S A 108:2957-62.

FI000 Factor 6

Evaluated by Alejandro Chade 15 Dec 2011

38. Morita T, Kakinuma Y, Kurabayashi A, Fujieda M, Sato T, Shuin T, Furihata $M$, Wakiguchi $H$ : Conditional VHL gene deletion activates a local NO-VEGF axis in a balanced manner reinforcing resistance to endothelium-targeted glomerulonephropathy. Nephrol Dial Transplant 201 I, 26:4023-3I.

FI000 Factor 6

Evaluated by Alejandro Chade 15 Dec 201 I 